\title{
W hat is the future for CSF biomarkers in the prediction of cognitive decline and Alzheimer's disease?
}
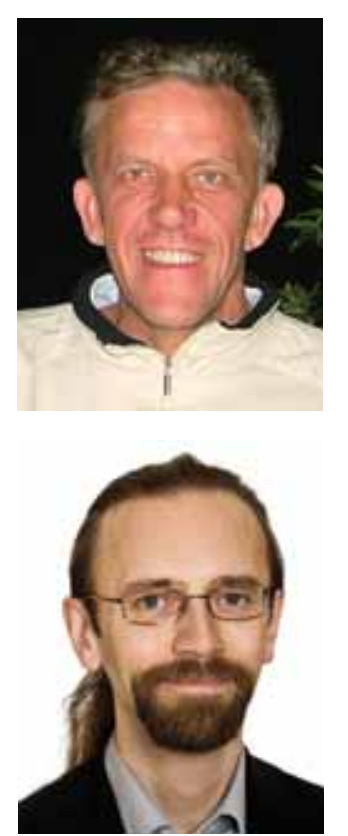

Kaj Blennowit \& HerrikZetterberg?

${ }^{\dagger}$ Author for correspondence ${ }^{1}$ T heSahlgrenska Academy at Göteborg U niversity, Clinical Neurochemistry Laboratory, Sahlgrenska U niversity $\mathrm{H}$ ospital, SE-431 80 M ölndal, Sweden Tel.: +46 313431 791; Fax: +43 313432 426; E-mail: kaj.blennow@ neuro.gu.se

2Sahlgrenska Academy at Göteborg U niversity, Clinical N eurochemistry Laboratory, Göteborg, Sweden

Tel.: +46313430 142; Fax: +46 313432 426; E-mail: henrik.zetterberg@ clinchem.gu.se

future part of $\mathrm{fsg}$
'The promise of therapy hasalso created a need forbiomarkers to enable the clinic al identific ation of the disea se at an early stage.'

Alzheimer's disease (AD) is the most common form of cognitive disorder in the elderly, and is a major health problem. It is now 100 years since Alois Alzheimer presented the first report on the disease, and described the characteristic findings of plaques and tangles in the cortical areas of the brain. Although it took almost 80 years until the molecular composition of these pathological hallmarks was revealed, knowledge on the molecular pathogenesis of $A D$ has grown rapidly during the last two decades.

Plaques are made of aggregated $\beta$-amyloid $(A \beta)$, which is a small peptide produced from the much larger amyloid precursor protein (APP), while tangles are made of an abnormally hyperphosphorylated form of the microtubule associated protein tau. D etails on the metabolic pathways and enzymes resulting in production of $A \beta$ from APP and the mechanism of $A \beta$ aggregation and toxicity, as well as the kinases and phosphatases balancing tau phosphorylation, are now well known [1]. Intense worldwide research efforts have also been undertaken to translate these advances into therapeutic strategies. As a result, several promising drug candidates with disease-modifying effects, such as A $\beta$ immunotherapy and secretase modulators, are now being tested in several clinical trials. The promise of therapy has also created a need for biomarkers to enable the clinical identification of the disease at an early stage. Early diagnosis will be of great importance since disease-modifying drugs are likely to be most effective in the earlier stages of the disease, before neurodegeneration is too severe and widespread.

Cerebrospinal fluid biomarkers

Since the cerebrospinal fluid (CSF) is in direct contact with the brain extracellular fluid, biochemical changes in the brain will be reflected in the CSF. CSF biomarkers for AD should reflect the central pathogenic processes in the brain. Candidate biomarkers for these pathogenic processes include total tau $(T-\tau)$ as a marker for the neuronal degeneration, $A \beta 42$ as a marker for plaque formation and phosphorylated tau $(P-\tau)$ as a marker for tau hyperphosphorylation [2].

To obtain CSF, a lumbar puncture (LP) must be performed. This has made the implementation of CSF analyses in AD research more difficult, since LP may be regarded invasive and has been avoided due to fear of complications in the form of post-LP headache. H owever, the use of small-size needles and atraumatic techniques has reduced the risk of this complication, and several large prospective studies have shown that the incidence of post-LP headache is marginal in elderly with cognitive disturbances [3-5]. This has made CSF analyses a rapidly expanding research field, and has paved the way for the introduction of LP in clinical routine use [5].

\section{CSF biomarkers for AD diagnosis}

The three candidate CSF biomarkers $T-\tau, P-\tau$ and $A \beta 42$ have been extensively evaluated in numerous scientific studies. Very consistently, all studies have found a marked increase in both CSF $T-\tau$ and $P-\tau$ accompanied by a marked decrease in AB42 in AD cases with dementia (for review see $[2,6])$.

\section{'CSF biomarkers for AD should reflect the central pathogenic processes in the brain.'}

The diagnostic performance of these CSF biomarkers to discriminate $A D$ from nondemented aged individuals is high, with sensitivity and specificity figures of $80-90 \%$ [2,6]. $\mathrm{N}$ ormal CSF levels are found in several important differential diagnoses, such as depression and Parkinson's disease, and P- $\tau$ especially aids to differentiate $A D$ from other dementias, such as fronto-temporal dementia and Lewy body dementia $[7,8]$.

CSF biomarkers to identify incipient $A D$ in mild cognitive impairment Mild cognitive impairment ( $\mathrm{MCl}$ ) is an agerelated syndrome characterized by mild memory impairment, which can be verified by objective 
measures, but without other cognitive symptoms indicative of dementia [9]. $\mathrm{M} \mathrm{Cl}$ is an etiologically heterogeneous disorder; many $\mathrm{M} \mathrm{Cl}$ cases have incipient $A D$ (i.e., have early $A D$ pathology and will progress to $A D$ with dementia), while others have a benign form of $\mathrm{M} \mathrm{Cl}$ related to aging and, in some $\mathrm{M} \mathrm{Cl}$ cases, cerebrovascular disease may contribute to the memory impairment [9].

Recent research efforts on CSF biomarkers have been directed to evaluate biomarkers to identify incipient $A D$ in patients with $\mathrm{MCl}$ [2]. Initial studies showed that the combination of $\mathrm{T}-\tau$ and $A \beta 42$ have a high predictive power to identify incipient $\mathrm{AD}$ in $\mathrm{M} \mathrm{Cl}$ cases [2]. Recent studies with extended clinical follow-up periods show that the combination of all three CSF biomarkers ( $T-\tau$, $\mathrm{P}-\tau$ and $\mathrm{A} \beta 42$ ) may have a predictive value as high as $95 \%$ to differentiate $\mathrm{M} \mathrm{Cl}$ cases with progression to $\mathrm{AD}$ from stable $\mathrm{M} \mathrm{Cl}$ cases and $\mathrm{M} \mathrm{Cl}$ cases with other types of underlying pathology [10].

\section{CSF biomarkers to identify}

AD preclinically

Some studies have also examined if CSF biomarkers may be useful to predict $A D$ at the pre clinical stage, that is, in elderly without any cognitive symptoms. Two population-based studies have found a significant reduction in CSF A 342 in cognitively normal elderly people that later developed dementia [11,12]. In the same material, there was no significant change in CSF $T-\tau$ or $P-\tau$ in individuals that later developed AD [12 \& Skoog I et al., Unpublished D ata].

'CSF bioma rkers, espec ia lly CSF A $\beta 42$, may predict prec linic aI $A D$ in cognitively norma l elderly ind ivid ua Is.'

A recent clinical study also found that CSF $A \beta 42$, but not $T-\tau$ and $P-\tau$, predict cognitive decline in the healthy elderly [13]. Another study based on a clinical patient sample showed that both the CSF T- $\tau: A \beta 42$ ratio and the $P-\tau: A \beta 42$ ratio predict cognitive decline with high confidence [14]. These data show that CSF biomarkers, especially CSF $A \beta 42$, may predict preclinical $A D$ in cognitively normal elderly individuals.

\section{CSF biomarkers in treatment trials}

Identification of the clinical effect of a drug using rating scales requires large patient materials and extended treatment periods in a slowly progressive disorder such as $A D$, especially for disease-modifying drugs with a potential to slow down the degenerative process, but without any direct effects on the symptoms. These new types of drugs are often evaluated on AD transgenic mice, but these animal models have a low predictive power for treatment efficacy in patients with sporadic AD [1]. To bridge the gap between animal studies and large clinical trials, and to help select the most promising drug candidates, short-term pilot studies using biomarker information to detect desired biochemical drug effects may be a valuable approach.

\section{‘...CSF biomarkers ma y be valua ble tools in future treatment trials on disea se-mod ifying drugs in AD.'}

Treatment trials with acetylcholine esterase (AChE) inhibitors may serve as a proof-of-concept for the potential of CSF biomarkers to identify and monitor the biochemical effect of a drug in AD. Such studies have found a marked increase in CSF AChE activity during treatment, which is dose-dependent and may be linked to both the mechanism of action for the drugs and the clinical outcome $[15,16]$. By contrast, there is no change in CSF $T-\tau, P-\tau$ or $A \beta 42$ during treatment with $A C h E$ inhibitors $[16,17]$. These data suggest that an adequate CSF biomarker is capable not only of identifying the biochemical effect of drugs, but al so to differentiate between different compounds in a clinically relevant manner.

The very low intraindividual variability of $T-\tau$, $P-\tau$ and $A \beta 42$ levels in studies with longitudinal CSF samples during 6 months and 2 years $[17,18]$ also paves the way for use of these markers in clinical trials. At present, it is uncertain how CSF A $\beta 42$ might react upon treatment with efficacious amyloid-targeting drugs in man [19]. However, studies in transgenic mice suggest that reduced CSF A $\beta 42$ levels are to be expected for $\gamma$-secretase inhibitors [20], and acute administration of the $\gamma$-secretase inhibitor BM S-299897 in guinea pigs was found to reduce all cortical, CSF and plasma levels of $A \beta$ [21]. These data give promise that CSF biomarkers may be valuable tools in future treatment trials on disease-modifying drugs in $A D$.

Financial \& competing interests disclosure The authors have no relevant affiliations or financial involve ment with any organization or entity with a financial interest in or financial conflict with the subject matter or materials discussed in the manuscript. This includes employment, consultancies, honoraria, stock ownership or options, expert testimony, grants or patents received or pending, or royalties

No writing assistance was utilized in the production of this manuscript. 


\section{The future for CSF biomarkers in the prediction of cognitive decline \& AD - EDIT O RIAL}

Bibliography

1. Blennow K, de Leon M J, Zetterberg $\mathrm{H}$ : Alzheimer's disease. Lancet 368, 387-403 (2006).

2. Blennow $\mathrm{K}, \mathrm{H}$ ampel $\mathrm{H}$ : Cerebrospinal fluid markers for incipient Alzheimer's disease. Lancet N eurol. 2, 605-613 (2003).

3. Blennow $K$, Wallin $A, H$ äger $O$ : Low frequency of post-lumbar puncture headache in demented patients. Acta $\mathrm{N}$ eurol. Scand. 88, 221-223 (1993).

4. Peskind ER, Riekse R, Q uinn JF et al.: Safety and acceptability of the research lumbar puncture. Alzheimer Dis. Assoc. Disord. 19, 220-225 (2005).

5. Andreasen $N, M$ inthon $L, D$ avidsson $P$ et al.: Evaluation of $C S F-\tau$ and $C S F-A \beta 42$ as diagnostic markers for Alzheimer's disease in clinical practice. Arch. N eurol. 58, 373-379 (2001).

6. Blennow K: CSF biomarkers for Alzheimer's disease: use in early diagnosis and evaluation of drug treatment. Expert Rev. M ol. Diagn. 5, 661-672 (2005).

7. Buerger K, Zinkowski R, Teipel SJ et al.: Differential diagnsis of Alzheimer's disease with cerebrospinal fluid levels of tau protein phosphorylated at threonine 231. Arch. N eurol. 59, 1267-1272 (2002).

8. $\mathrm{H}$ ampel $\mathrm{H}$, Buerger $\mathrm{K}$, Zinkowski R et al.: M easurement of phosphorylated tau epitopes in the differential diagnosis of Alzheimer disease: a Comparative Cerebrospinal Fluid Study. Arch. Gen. Psychiatry 61, 95-102 (2004).
9. Petersen $\mathrm{RC}$, Smith $\mathrm{GE}$, Waring $\mathrm{SC}$, Ivnik RJ, Tangalos EG, Kokmen E: $M$ ild cognitive impairment: clinical characterization and outcome. Arch. N eurol. 56, 303-308 (1999).

10. $\mathrm{H}$ ansson $\mathrm{O}$, Zetterberg $\mathrm{H}$, Buchhave $\mathrm{P}$, Londos E, Blennow K, M inthon L: Association between CSF biomarkers and incipient Alzheimer's disease in patients with mild cognitive impairment: a follow-up study. Lancet N eurol. 5, 228-234 (2006).

11. Skoog I, D avidsson P, Aevarsson 0 Vanderstichele $H$, Vanmechelen $E$, Blennow K: Cerebrospinal fluid $\beta$-amyloid 42 is reduced before the onset of sporadic dementia: a population-based study in 85-year-olds. D ement. Geriatr. Cogn. D isord. $15,169-176$ (2003).

12. Gustafson D R, Skoog I, Rosengren L, Zetterberg $\mathrm{H}$, Blennow K : Cerebrospinal fluid $\beta$-amyloid 1-42 concentration may predict cognitive decline in older women. J. N eurol. N eurosurg. Psychiatr. 78, 461-464 (2007).

13. Stomrud $\mathrm{E}, \mathrm{H}$ ansson $\mathrm{O}$, Blennow $\mathrm{K}$, $M$ inthon $L$, Londos $E$ : Cerebrospinal fluid biomarkers predict decline in subjective cognitive function over 3 years in healthy controls. D ement. Geriatr. Cogn. D isord. 24, 118-124 (2007).

14. Fagan $A M$, Roe CM , Xiong $C$, $M$ intun $M A, M$ orris J $C, H$ oltzman D M : Cerebrospinal fluid $\tau / \beta$-amyloid(42) ratio as a prediction of cognitive decline in nondemented older adults. Arch. N eurol. 64, 343-349 (2007).
15. Davidsson P, Blennow K, Andreasen N, Eriksson B, M inthon L, H esse C: D ifferential increase in cerebrospinal fluid-acetylcholine esterase after treatment with acetylcholine esterase inhibitors in patients with Alzheimer's disease. N eurosai. Lett. 300, 157-160 (2001).

16. Parnetti $L$, Amici $S$, Lanari $A$ et al.: Cerebrospinal fluid levels of biomarkers and activity of acetyl cholinesterase and butyrylcholinesterase in AD patients before and after treatment with different $\mathrm{AChE}$ inhibitors. N eurol. Sci. 23, S95-S96 (2002).

17. Blennow $K, Z$ Zetterberg $H, M$ inthon $L$ et al.: Longitudinal stability of CSF biomarkers in Alzheimer's disease. N eurosci. Lett. 419, 18-22 (2007).

18. Zetterberg $H$, Pedersen $M$, Lind $K$ et al.: Intra-individual stability of CSF biomarkers for Alzheimer's disease over two years. J. Alzheimers D is, 12, 255-260 (2007).

19. Gilman $S$, Koller M, Black RS et al.; AN 1792(Q S-21)-201 Study Team: Clinical effects of $A \beta$ immunization (AN 1792) in patients with $A D$ in an interrupted trial. N eurology 64, 1553-1562 (2005).

20. Siemers ER, Q uinn JF, Kaye J et al.: Effects of a $\gamma$-secretase inhibitor in a randomized study of patients with Alzheimer's disease. $N$ eurology 66, 602-604 (2006).

21. Lanz TA, H imes CS, Pallante $G$ et al.: The $\gamma$-secretase inhibitor $\mathrm{N}$-[N - $(3,5$ difluorophenacetyl)-L-alanyl]-Sphenylglycine t-butyl ester reduces $A \beta$ levels in vivo in plasma and cerebrospinal fluid in young (plaque-free) and aged (plaquebearing) T g2576 mice. J. Pharmacol. Exp. Ther. 305, 864-871 (2003). 